\title{
SISTEMA DE INFORMAÇÃO: UMA FERRAMENTA PARA QUALIDADE DA ATENÇÃO A SAÚDE DAS DETENTAS EM SERGIPE - BRASIL
}

\author{
INFORMATION SYSTEM: A TOOL FOR QUALITY HEALTH CARE IN FEMALE \\ INMATES SERGIPE -BRAZIL
}

\author{
Luiz Eduardo Oliveira ${ }^{1}$ \\ Verônica Teixeira Marques ${ }^{2}$ \\ Cristiane Costa da Cunha Oliveira ${ }^{3}$
}

\section{RESUMO}

O valor de uma política pública para efetivação da ação governamental é questão relevante na atenção à saúde e dos serviços disponibilizados pelo Estado. Este estudo teve como objetivo principal investigar como as políticas públicas em saúde para as presas estão sendo implementadas dentro do Sistema Penitenciário de Sergipe-Brasil e também analisar se existem novas tecnologias e se estão sendo disponibilizadas pelas políticas de saúde prisional. As mulheres privadas de liberdade do presídio feminino responderam a um questionário semiestruturado e revelaram que havia necessidades de saúde não preenchidas, inclusive no acesso aos serviços de saúde e profissionais em saúde, o que sugere que a Política Nacional para a Saúde Prisional não vem sendo cumprida com efetividade, havendo urgência de melhorias na rede de atenção à saúde no sentido de efetivar ações preventivas e curativas.

PALAVRAS-CHAVE: Saúde. Sistema prisional. Presídio Feminino. Sistema de Informação.

\section{ABSTRACT}

The value of a public policy for effective government action is relevant issue in health care and services provided by the state. This study aimed to investigate how public health policies for the tusks are being implemented within the prison system in Sergipe-Brazil and also look for new technologies and if those have being made available by the prison health policies. Women deprived of freedom of a female prison answered a semi-structured questionnaire and revealed that there were health needs not met, including access to health and health professional services, which suggests that the National Policy for Health Prison has not been fulfilled with effectiveness, and also that there is urgent improvements in health care network in order to carry out preventive and curative actions.

KEYWORDS: Health. Prison System. Female Prison. Information Sy stem.

\footnotetext{
${ }^{1}$ Mestre em Direitos Humanos. Professor de Direito da Faculdade Sergipana (FASER- SE/BRASIL). Telefone: 79 99864-1122. E-mail: eduardoabril1965@gmail.com.

2 Doutora em Sociologia. Professora do Programa de Mestrado em Direitos Humanos da Universidade Tiradentes, Sergipe (UNIT- SE/BRASIL). E-mail: veronica.marques@hotmail.com.

${ }^{3}$ Doutora em Saúde Coletiva/Odontologia. Professora do Programa de Mestrado e Doutorado em Saúde e Ambiente da Universidade Tiradentes, Sergipe. E-mail: criscunhaoliva@yahoo.com.br.
} 


\section{INTRODUÇÃO}

A necessidade de adoção de medidas preventivas ou curativas faz parte da gestão de governo diante de tantas demandas pelas quais precisa realizar ações efetivas para governar. O contexto, a época e a participação dos elaboradores de qualquer política pública, encontram-se inseridos em uma arena onde ocorre uma intermediação de interesses muitas vezes perverso.

Na conjuntura atual o ato de governar já não comporta só um olhar para dentro, para as questões locais. Há uma governança mundial com reflexos em todos os países e em todas as culturas. As políticas públicas são articuladas, pensadas e discutidas em nível internacional por diversos atores sociais sendo esses os que intervêm de forma direta ou indireta no processo de elaboração de uma determinada política e, quanto maior for a participação da sociedade civil nesse processo, maior será a cobrança na efetivação dos resultados esperados (DIAS, 2012).

De igual modo, as políticas públicas para a questão penitenciária demandam um debate amplo, nas mais variadas áreas do conhecimento, uma vez que a população privada de liberdade, diante de sua vulnerabilidade e especificidade, requer um envolvimento de profissionais capacitados em várias áreas, inclusive com habilitação nas novas tecnologias disponíveis.

O ambiente prisional por si só constitui, no imaginário popular, um local de sacrifício, punição e "pagamento", principalmente para países como o Brasil onde a população "em liberdade" não dispõe das condições básicas em saúde. O modelo de sistema penitenciário adotado pelo Brasil pode ser objeto de questionamento no sentido do que se pretende proteger, a quem se pretende e pode castigar e como punir desde que se observe o estabelecido em nível legal, com cumprimento das políticas públicas adotadas. Os vários organismos e organizações de proteção dos direitos humanos têm revelado preocupações com as sistemáticas violações do direito à saúde da população privada de liberdade, como a Comissão Interamericana de Direitos Humanos ${ }^{4}$ e a Corte Interamericana de Direitos Humanos ${ }^{5}$. As políticas públicas em saúde são reflexos de um forte debate mundial com interferência no ordenamento jurídico brasileiro, basta

\footnotetext{
${ }^{4}$ Comissão Interamericana de Direitos Humanos. MC 199-11 - Personas privadas de libertad en la Prisión Profesor Aníbal Bruno, Brasil. (Acesso em 2015 julho 12). Disponível em: http://www.oas.org/es/cidh/ $\mathrm{ppl} /$ proteccion/cautelares.asp

${ }^{5}$ Corte Interamericana de Direitos Humanos. Corte IDH. Asunto del Complejo Penitenciario de Pedrinhas respecto de Brasil. Resolución Corte Interamericana de Derechos Humanos de 14 de noviembre de 2014. (Acesso em 2015 julho 12) Disponível em: http://www.corteidh.or.cr/index.php/mapa-interactivo Serv. Soc. \& Saúde, Campinas, SP v. 14, n. 2 (20), p. 211-224, jul./dez. 2015 ISSN 1676-6806
} 
analisar o impacto da Convenção Mundial de Saúde de Ottawa, Canadá, 1986 que irradiou, através dos princípios de promoção da saúde, entre eles a reorientação dos serviços de saúde, e a criação de políticas favoráveis à saúde, a universalidade e integralidade da atenção à saúde para a população brasileira, através do Sistema Único de Saúde, com amparo constitucional (WHO, 1986, BRASIL, 1988).

Em se tratando de saúde nas unidades prisionais, os profissionais em saúde, técnicos da informação e gestores, tanto do Ministério da Saúde como do Ministério da Justiça, devem estar preparados para, a contento, lidarem com as novas tecnologias como redes, digitalização, programas específicos para a população privada de liberdade que permita ao setor da saúde prisional ser eficaz. Não basta prever a importância das novas tecnologias diante de um quadro caótico pelo qual passa a população brasileira e no caso específico a população privada de liberdade há muito tempo, urge a adoção de novas tecnologias que facilitem a implementação das políticas públicas.

Em Sergipe/Brasil os programas como prontuários eletrônicos, agenda digital, prescrição eletrônica são expressões conhecidas pelos gestores, porém com utilização incipiente, sugerindo que as noções de práticas em saúde e justiça precisam ser discutidas, estudas e analisadas em rede para eficácia das ações planejadas através de políticas públicas. A própria noção do trabalho em rede parece demandar uma análise aprofundada.

Neste contexto é oportuno que sejam realizados diagnósticos, tanto da efetividade das tecnologias aplicáveis à saúde, como da avaliação das políticas e programas que estão sendo realizados no Brasil e, mais especificamente, no Estado de Sergipe para o Sistema Prisional.

Assim, os objetivos deste estudo foram: i) analisar os sistemas de informação disponibilizados pelas políticas de saúde prisional e sua possível influência na qualidade da atenção a saúde das presas sergipanas; ii) verificar se o sistema de informação de saúde no estado de Sergipe/Brasil tem sido utilizado como ferramenta oportuna para a gestão de políticas públicas para o sistema prisional e iii) analisar a qualidade da atenção à saúde, na percepção das mulheres sergipanas privadas de liberdade. 


\section{MATERIAIS UTILIZADOS}

A metodologia deste estudo é referida como pesquisa seccional do tipo multimétodo no período 2013-2014. Foram aplicados questionários semiabertos a presas, após aprovação do Comitê de Ética da Universidade Tiradentes, com número de Protocolo CEP 040712R.

A amostra probabilística contou com 61 mulheres privadas de liberdade, selecionados ao azar, de um total de 273 em uma unidade penitenciária feminina de Sergipe - PREFEM, com representação significativa de presas que consentiram em participar da investigação.

Adicionalmente foi realizada busca de dados secundários no Portal da Saúde do Ministério da Saúde ${ }^{6}$, onde foram disponibilizados os principais sistemas que auxiliam a implementação da saúde penitenciária, como o Cadastro Nacional de Estabelecimentos de Saúde - CNES, o Sistema de Informação de Agravos de Notificação - SINAN, o Sistema de Informação da Atenção Básica - SIAB, o Sistema de Informações Ambulatoriais do SUS - SIASUS, o Sistema de Informações sobre Mortalidade - SIM, o FormSUS e o Sistema Integrado de Informação Penitenciária - INFOPEN. Esses dados foram contrapostos com visita a gestores da saúde do sistema prisional sergipano.

\section{RESULTADOS E A DISCUSSÃO}

Há uma predominância de homens nos presídios brasileiros, porém o número de mulheres no sistema prisional tem crescido vertiginosamente, conforme é possível verificar no Mapa do Encarceramento de 2015 que foi elaborado no âmbito do projeto de cooperação técnica BRA/12/018 - Desenvolvimento de Metodologias de Articulação e Gestão de Políticas Públicas para Promoção da Democracia Participativa, entre a Secretaria Geral da Presidência da República e o Programa das Nações Unidas para o Desenvolvimento - PNUD ${ }^{7}$.

\footnotetext{
${ }^{6}$ Ministério da Saúde. Portal da Saúde. SUS. SAS. DAPES. Saúde no Sistema Prisional. (Acesso em 2015 julho 12) Disponível em: http://portalsaude.saude.gov.br/index.php/oministerio/principal/secretarias/sas/saude-no-sistema-prisional ${ }^{7}$ Brasil. Presidência da República. Secretaria Geral. Mapa do encarceramento: os jovens do Brasil / Secretaria-Geral da Presidência da República e Secretaria Nacional de Juventude. - Brasília: Presidência da República, 2015. (Acesso em 2015 julho 12). Disponível em: http://www.pnud.org.br/arquivos/encarceramento_WEB.pdf

Serv. Soc. \& Saúde, Campinas, SP v. 14, n. 2 (20), p. 211-224, jul./dez. 2015 ISSN 1676-6806
} 
Também reitera essa situação o relatório do INFOPEN que registra que "No período de 2000 a 2014 o aumento da população feminina foi de 567,4\%, enquanto a média de crescimento masculino, no mesmo período, foi de 220,20\%”8.

No estado sergipano os dados do INFOPEN também indicam que entre 2007 e 2014, enquanto houve um aumento de 79\% da população masculina nos cárceres, em relação às mulheres houve um aumento de $184 \%$.

De acordo com o Departamento Penitenciário Nacional - DEPEN- nos últimos 12 anos a população carcerária feminina aumentou 256\%, e as mulheres representavam cerca de 7\% da população carcerária brasileira, o que correspondia a aproximadamente 36 mil presas ${ }^{9}$. De acordo com a pesquisa realizada nos presídios sergipanos os crimes mais praticados pelas 61 mulheres que participaram da amostra e, considerando o total de crimes praticados por mulheres, foram: - crimes contra a pessoa: 6,01\% - crimes contra o patrimônio: $19,67 \%$ - crimes contra a paz pública: $0 \%$ - crimes contra a fé pública: 0\% - tráfico: 69,39\%.

A unidade PREFEM apresenta uma grande quantidade de mulheres privadas de liberdade com idade entre 18 e 29 anos, que representa 50,9\% das pesquisadas. Com relação à renda um percentual de 45,9\% declarou receber menos que um salário mínimo. O nível de escolaridade declarado pelas mulheres encarceradas revelou que um elevado índice delas possuía ensino fundamental incompleto (67,3\%) e que 41\% delas relatou exercer a atividade de autônoma. Dados que servem de alerta, aliado ao fato do crescente aumento de mulheres encarceradas.

Em Sergipe onde só há uma unidade prisional destinada às mulheres privadas de liberdade (Figura 1), elas são postas em um só lugar, o que pode resultar em locais distantes de onde vivem e provocar um impedimento para visitas familiares e de redes de apoio. Essa dificuldade foi evidenciada pelo Guia Sobre Gênero da Organização Panamericana da Saúde (UNIDOC. OPAS/OMS- UNB, 2012).

\footnotetext{
${ }^{8}$ Fonte: Levantamento Nacional de Informações Penitênciárias Infopen Mulheres - junho de 2014; p. 05. Disponível em: http://www.justica.gov.br/noticias/estudo-traca-perfil-da-populacao-penitenciariafeminina-no-brasil/relatorio-infopen-mulheres.pdf. Acesso em: 06 nov 2015.

${ }^{9}$ Ministério da Justiça. Governo Federal. (Acesso em 2015 julho 12) Disponível em: http:// www.justica.gov.br/noticias/numero-de-mulheres-presas-aumentou-256-em-12-anos Serv. Soc. \& Saúde, Campinas, SP v.14, n. 2 (20), p. 211-224, jul./dez. 2015 ISSN 1676-6806
} 


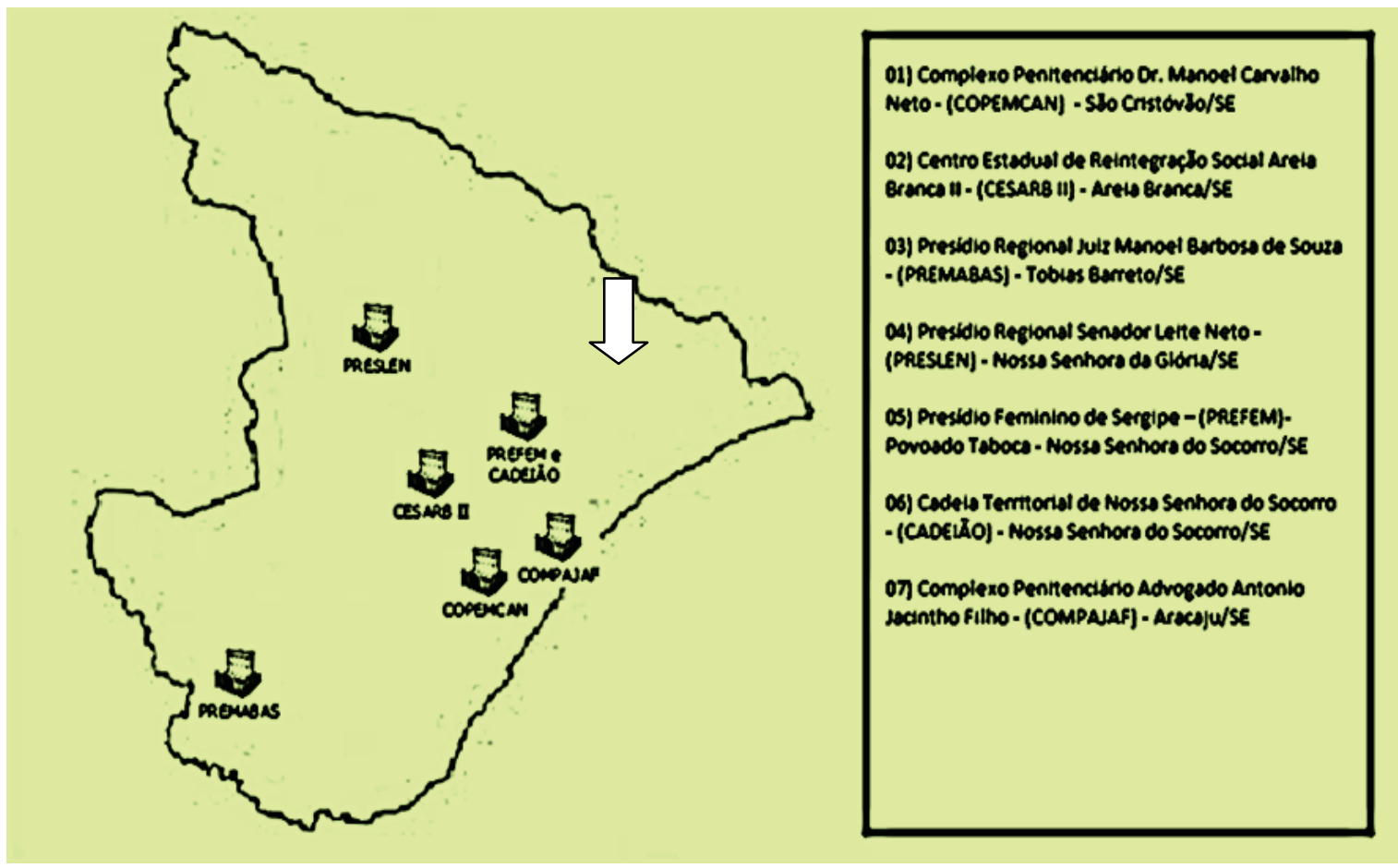

Fonte: Elaborado pelo autor

Figura 1: Mapa ilustrativo das unidades prisionais do Estado de Sergipe /2014

O relato das mulheres privadas de liberdade - 75,4\% quando da pesquisa de campo em Sergipe/Brasil, revelou que elas possuíam algum tipo de necessidade de saúde e apenas 55,7\% disseram ter sido acesso aos serviços de saúde, embora 18\% tenham afirmado que não necessitavam dos serviços em saúde, conforme Figura 2.

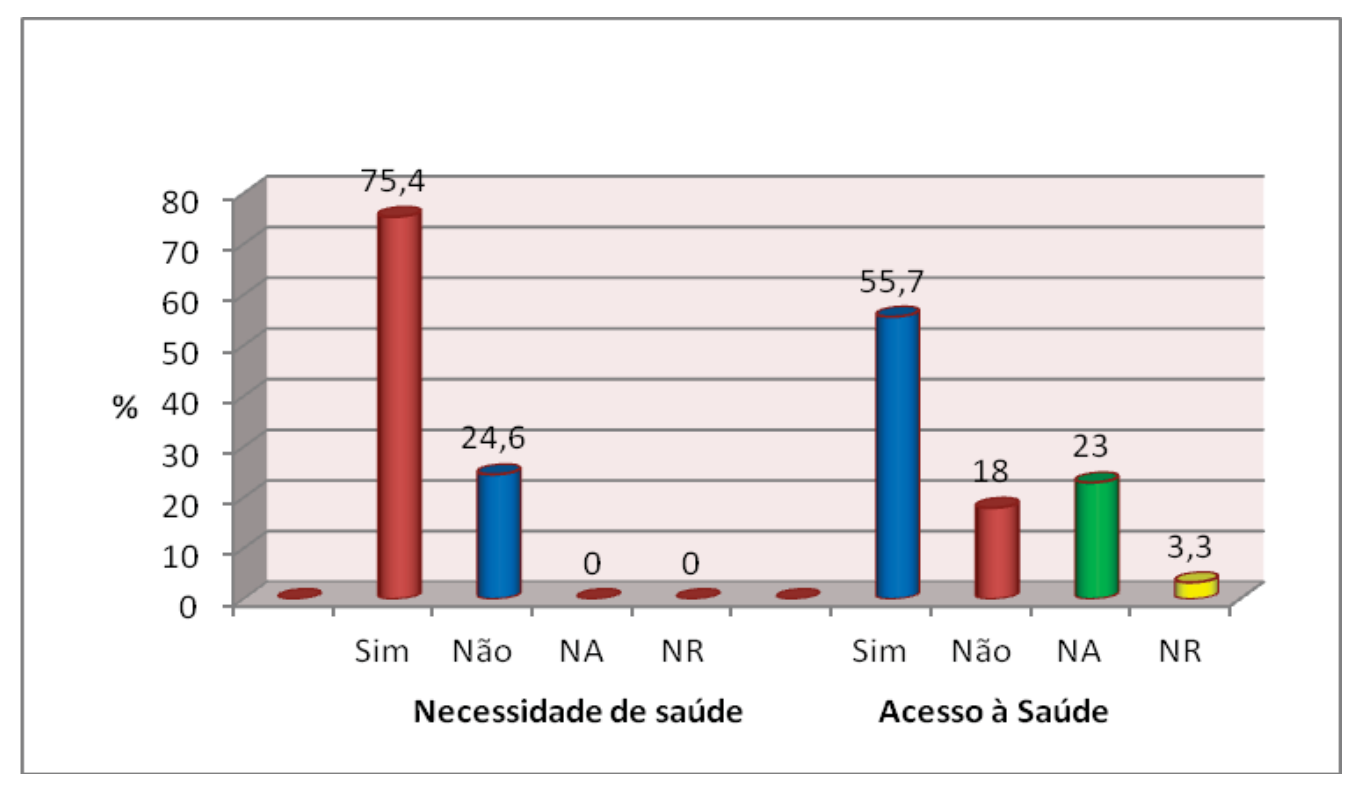

Figura 2- Análise das necessidades de assistência à saúde e acesso aos serviços de saúde pelas presas PREFEM Sergipe-Brasil. Agosto a Dezembro/2013 
Pode-se dizer que o ambiente prisional do presídio feminino em Sergipe PREFEM apresenta relatos fornecidos pelas mulheres privadas de liberdade da existência de enfermidades cardiovasculares e metabólicas, doenças infectocontagiosas e parasitárias, DST, doenças de pele, bem como outros sintomas, apesar de um considerável número de presas que informaram não ter contraído doenças no período de internamento, conforme Figura 3.

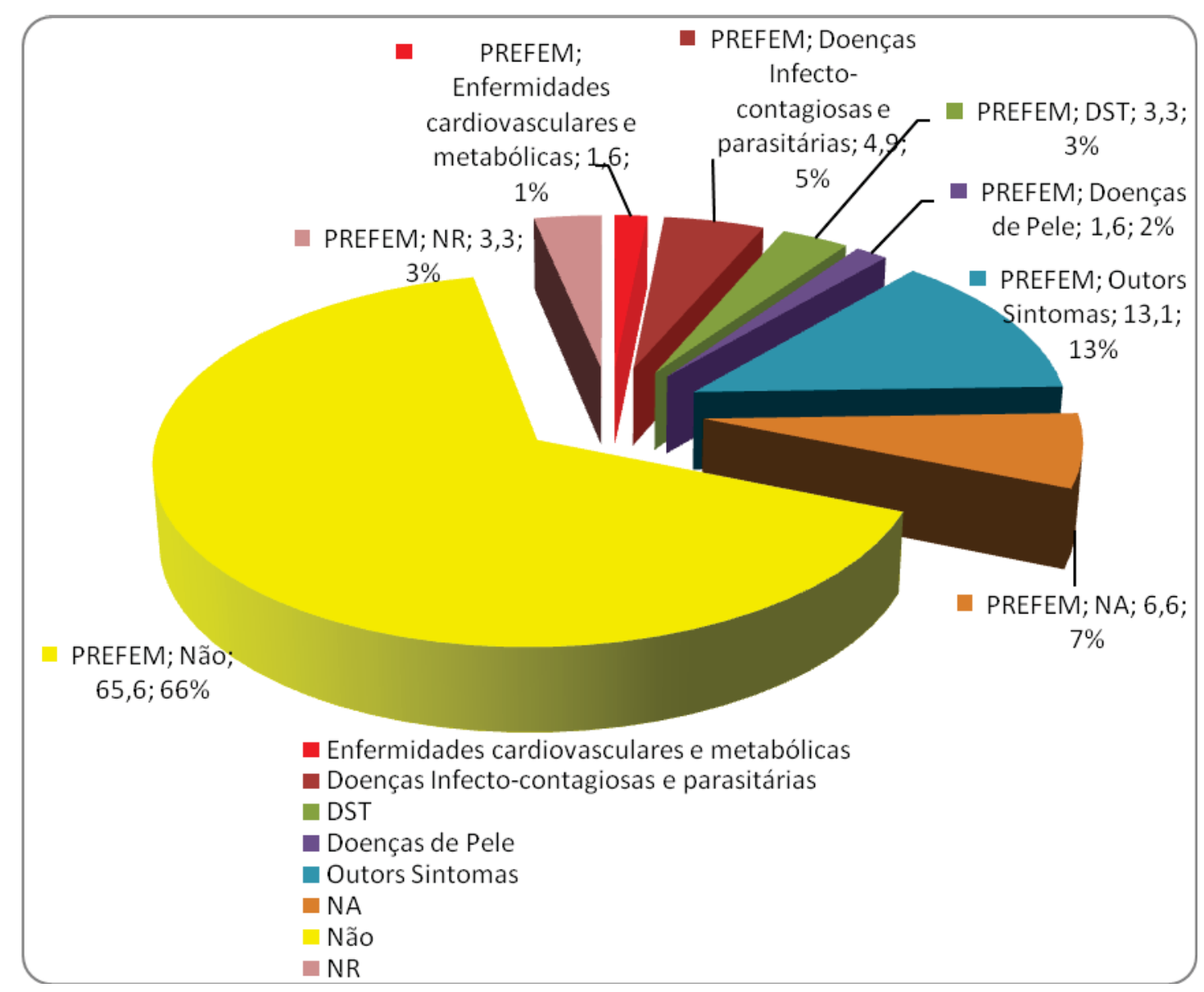

Figura 3 - Enfermidades contraídas pelas presas. PREFEM Sergipe-Brasil. Agosto a Dezembro/2013.

Esse grande percentual que afirma não ter contraído nenhuma doença no período de internamento pode ser reflexo do acompanhamento inadequado dentro da unidade prisional já que 75,4 \% havia afirmado que possuía necessidade de saúde (Figura 3). Importante mencionar que a presença de equipes de saúde no interior desta unidade prisional só foi possível mediante a intervenção do Ministério Público Estadual através 
da assinatura de termo de ajuste de conduta - TAC, celebrado em 30 de junho de 2014 que foi firmado por representantes do Ministério Público de Sergipe, e representantes da Secretaria de Estado da Saúde, Secretaria de Estado da Justiça e Defesa do Consumidor, Secretaria Municipal de Saúde de Aracaju, Secretaria Municipal de Saúde de Nossa Senhora do Socorro - onde se localiza o PREFEM, Secretaria Municipal de Saúde de São Cristóvão, Secretaria Municipal de Saúde de Nossa Senhora da Glória, Secretaria Municipal de Saúde de Areia Branca, cidades onde se localizam as demais unidades prisionais sergipanas.

O momento é oportuno para reflexão tendo em vista que se faz necessário que ocorra a implementação efetiva da Política Nacional de Atenção Integral à Saúde das Pessoas Privadas de Liberdade no Sistema Prisional que implica em equipes de saúde específicas para trabalhar neste ambiente (BRASIL, 2014).

Entretanto estas equipes não devem estar isoladas de um sistema de informação em rede que possa servir de ferramenta para planejamento efetivo por parte de gestores de saúde municipais e estaduais. Ressalta-se que no tocante aos Programas Brasileiros como o Cadastro Nacional de Estabelecimentos de Saúde - CNES; o Sistema Integrado de Informação Penitenciária - INFOPEN; o Sistema de Informação de Agravos de Notificação - SINAN; o Sistema de Informação da Atenção Básica - SIAB; o Sistema de Informações Ambulatoriais do SUS - SIASUS; Sistema de Informações sobre Mortalidade - SM; o FormSUS disponibilizados, observou-se que estes eram conhecidos pelos gestores porém, foi detectado até o momento desta pesquisa, que não havia mecanismos para coleta e análise dos dados de saúde referentes ao sistema prisional.

Também restou observado que a ideia de rede precisa ser sedimentada e compartilhada pelos profissionais em saúde e demais interessados. Neste sentido reserva-se oportuno que existam ferramentas dentro do sistema de informação em saúde que permitam filtrar os dados do sistema prisional provenientes de todos os subsistemas anteriormente referidos e assim proporcionar que tanto os gestores municipais e estaduais da saúde, bem como os gestores do sistema prisional possam acessar essas informações, em conjunto ou separadamente, proporcionando assim um compartilhar em rede de ações efetivadas.

Entre os programas e tecnologias de saúde estabelecidos para o Sistema Prisional no Brasil e adotados também em Sergipe, foi constatado que os prontuários eletrônicos, a agenda digital, a prescrição eletrônica são expressões conhecidas pelos Serv. Soc. \& Saúde, Campinas, SP v. 14, n. 2 (20), p. 211-224, jul./dez. 2015 ISSN 1676-6806 
gestores, porém pouco utilizadas. Os prontuários eletrônicos embora existentes, ainda são muitas vezes confeccionados manualmente pelos profissionais que atuam no atendimento e transcritos por outro servidor para alimentar o sistema de informação. Sabe-se que no Brasil ainda existem dificuldades na sua implementação, a saber o custo de implantação e a necessidade de capacitação dos profissionais (GONÇALVES et al., 2013).

No Brasil, e em Sergipe mais especificamente, o trabalho em rede utilizado pelos profissionais de saúde se baseia em redes temáticas que são interligadas e funcionam como rede de atenção primária, psicossocial, especializada e urgência/emergência, porém sem referência a unidades prisionais específicas. O prontuário eletrônico utilizado e operacionalizado através da versão 1.3.11, conhecido como sistema ESUS, encontra-se em fase de substituição pela versão 2.0 e possivelmente possibilitará uma melhor elaboração de relatórios.

\section{As contribuições e o interesse da comunicação em relação ao estado da arte ou às práticas atuais}

No contexto brasileiro, buscando responder à problemática da vulnerabilidade dos presos às doenças transmissíveis mais relevantes para o planejamento em saúde pública foi elaborado, de forma conjunta, pelo Ministério da Saúde e do Ministério da Justiça, o Plano Nacional de Saúde no Sistema Prisional - PNSSP - criado através da portaria interministerial $\mathrm{n}^{\circ} 1.777$, de 2003, que sedimentou o compromisso do SUS perante a população carcerária brasileira, ao adotar a universalidade e a equidade das ações e serviços de atenção básica para os presos nas unidades prisionais, inclusive através de equipes interdisciplinares de saúde, de forma a garantir cidadania na perspectiva dos direitos humanos (BRASIL, 2003).

Entretanto o PNSSP, por ser um plano, apresentou ação restrita no tempo e teve sua limitação condicionada a opção de governos e governantes. Havia, portanto o desafio da implementação de uma política que pudesse qualificar e quantificar os dados epidemiológicos, através de metas e indicadores da saúde nas unidades prisionais e ainda possibilitasse seu monitoramento.

Nesse cenário foi estabelecida a Política Nacional de Atenção Integral à Saúde das Pessoas Privadas de Liberdade no Sistema Prisional - PNAISP - no âmbito do 
Sistema Único de Saúde, através da Portaria Interministerial $n^{\circ}$ 1, de Janeiro de 2014. Essa política teve no seu bojo o respeito aos princípios de direitos humanos e justiça social e integralidade da atenção à saúde da população carcerária no conjunto de ações de promoção, proteção, prevenção, assistência e recuperação, assim como vigilância em saúde.

A PNAISP se encaixou no cenário internacional onde a diretriz da Organização Mundial de Saúde para a saúde dos presos, publicada em 2014, orientava que o cuidado deveria ser baseado nas necessidades e reconhecimento dos direitos humanos, com utilização de equipes, recursos e facilidades semelhantes aos oferecidos às pessoas que não se encontram em situação de privação de liberdade. Ressaltava ainda a importância da continuidade do tratamento e a autonomia dos profissionais das equipes de saúde (WHO, 2014).

Para que a operacionalização dessa política (PNAISP) fosse possível foi implementada a portaria 482/2014 que instituiu que os serviços de saúde nos estabelecimentos prisionais seriam conformados de acordo com a população prisional e o modo de funcionamento dos serviços (BRASIL, 2014b), sendo complementada pela portaria n n $^{305 / 2014}$ que estabeleceu normas para a inclusão no Sistema de Cadastro Nacional dos Estabelecimentos de Saúde (SCNES) das equipes e serviços que iriam fazer parte da Atenção Básica de Saúde Prisional. Foram estabelecidos também os tipos de equipes de saúde no sistema prisional (BRASIL, 2014c).

Importante salientar que como marco teórico para a atenção dos serviços de saúde para a população privada de liberdade há a Lei de Execução Penal, 1984, que no seu artigo 14 já prevê que a assistência em saúde deve disponibilizar o atendimento médico, farmacêutico e odontológico (BRASIL, 1984).

A presente pesquisa permite aferir que a única unidade prisional feminina em Sergipe tem reproduzido a exclusão e mantém um sistema de desigualdade social. Ficou evidenciado que parcela considerável das mulheres privadas de liberdade não havia sido atendida em suas carências básicas em saúde pelos profissionais habilitados, ainda que a maioria das entrevistadas tivesse relatado a necessidade de tratamentos e medicamentos. Na realidade prisional sergipana expressões como «prontuários eletrônicos», «agenda digital», «prescrição eletrônica», «intercâmbios em rede» ainda soam como uma realidade distante e necessitam de adequação às especificidades para o sistema prisional.

Os profissionais em saúde ainda lutam por questões básicas de sobrevivência no local de trabalho sendo passíveis inclusive de várias enfermidades motivadas pela Serv. Soc. \& Saúde, Campinas, SP v. 14, n. 2 (20), p. 211-224, jul./dez. 2015 ISSN 1676-6806 
superpopulação, condições de aprisionamento, etc. Este desafio deve ser precedido de políticas públicas estabelecidas através da participação dos gestores diretamente envolvidos na temática, de forma multidisciplinar e com um olhar macro e micro econômico social. A realidade nas unidades prisionais sergipanas em pouco difere da realidade nacional e o estudo do perfil dos presos é relevante na medida em que auxilia na compreensão da eficácia ou não das legislações e contribui para a criação de novas políticas públicas que servem positivamente para a reinserção dos detentos na sociedade “normal” (MARQUES et al, 2014).

O trabalho em rede é apontado como um meio para a resolução dos graves problemas de saúde no Brasil, bem como para o combate à violência, devendo ser baseado na solidariedade e na cooperação entre as organizações. Esse entendimento deve ser respaldado pela articulação política e na adoção de decisões de forma horizontal e que observe os princípios de igualdade, democracia, cooperação e solidariedade (BRASIL, 2012).

Para o funcionamento de uma rede faz-se necessário um bom sistema de troca de informações, de articulação institucional uma vez que são formadas por um complexo de gestores e executores de prestação de serviços que devem funcionar articulados e possuírem a exata compreensão de que sua existência pressupõe a troca de experiências para o enfrentamento de problemas concretos e que são de interesse da população em geral, principalmente para um país como o Brasil que monopoliza o processo de elaboração das políticas públicas e descentraliza a sua execução. Para tanto torna-se fundamental a participação do município para que este organize e estruture a rede de forma a envolver os mais diversos atores sociais, bem como a conexão com outras redes $^{14}$ e assim evitar a representação do Brasil perante os sistemas de proteção de direitos humanos por sucessivas violações de direitos humanos para as mulheres privadas de liberdade.

O entendimento do funcionamento das redes de atenção à saúde precisa ser disseminado não só para os gestores, mas principalmente para a comunidade em geral, pois a sua operacionalização se verifica quando os diversos nós são disponibilizados para a consecução do bem comum. 


\section{CONSIDERAÇÕES FINAIS}

Estabelecer políticas públicas em saúde para o sistema prisional brasileiro constitui um caminho importante e necessário para efetivação do estabelecido na Constituição Federal, nos tratados e convenções internacionais e em leis específicas.

A participação internacional torna-se um imperativo no sentido de fazer valer as realidades locais e as especificidades culturais, na busca da efetivação dos preceitos legais através de políticas públicas.

Uma vez que as ações em saúde são estabelecidas cada vez em maior profundidade por organismos internacionais, faz-se necessário o aprimoramento dos gestores, dos profissionais em saúde e dos profissionais envolvidos no sistema penitenciário, no sentido de lidarem com as novas tecnologias, como aliadas e facilitadoras.

Em Sergipe as informações referentes à saúde do Sistema Prisional não são acessados de forma específica, isto é, não existem tecnologias que permitam filtrar a informação da atenção prestada para as pessoas privadas de liberdade, bem como as doenças e agravos que existem nas unidades prisionais. É muito importante e oportuno que o Sistema de Informação em Saúde no Brasil possa ter mecanismos que facilitem a coleta e análise de dados referentes ao Sistema Prisional desde o município e unidades federativas do país, bem como possa ser disponibilizado para investigações científicas de maneira menos burocrática.

A percepção das presas sergipanas ressaltou que a maioria possui necessidades de saúde e embora um percentual importante afirme ter encontrado acesso aos serviços de saúde, esse é reflexo da atenção prestada pelo município às pessoas privadas de liberdade devido ao principio do SUS de universalidade da atenção. Entretanto não resulta da efetivação da política de saúde para o sistema prisional que prevê equipes específicas de saúde para o sistema prisional tanto em Sergipe, quanto no Brasil.

Recebido em 03.12.2015 - Aprovado em 15.12.2015 


\section{REFERÊNCIAS}

BRASIL. Lei n. ${ }^{\text {7.210, de }} 11$ de julho de 1984. Institui a Lei de Execução Penal. Diário Oficial da União, Poder Executivo, Brasília, DF, 13 jul. 1984. Disponível em: http://www.planalto.gov.br/ccivil_03/leis/17210.htm.

BRASIL. Constituição (1988). Constituição da República Federativa do Brasil: promulgada em 5 de outubro de 1988. Organização do texto: Juarez de Oliveira. 4.ed. São Paulo: Saraiva, 1990. 168 p. (Série Legislação Brasileira)

BRASIL. Lei $\mathbf{n}^{\mathbf{0}} \mathbf{8 . 0 8 0}$, de 19 de setembro de 1990. Dispõe sobre as Condições para Promoção, Proteção e Recuperação da Saúde, a Organização e o Funcionamento dos Serviços Correspondentes e dá Outras Providências. Disponível em: http://www.planalto.gov.br/ccivil_03/leis/18080.htm

BRASIL. Ministério da Saúde (BR); Ministério da Justiça (BR) Portaria Interministerial n. ${ }^{\mathbf{0}}$ 1.777, de 9 de setembro de 2003. Aprova o Plano Nacional de Saúde no Sistema Penitenciário. (Acesso em 2015 julho 04) Disponível em: www.saude.mg.gov.br/images/documentos/Portaria_1777.pdf

BRASIL. Ministério da Saúde. Secretaria de Atenção à Saúde. Departamento de Ações Programadas Estratégicas. Linha de cuidado para a atenção integral à saúde de crianças, adolescentes e suas famílias em situação de violências: orientação para gestores e profissionais de saúde / Ministério da Saúde. Secretaria de Atenção à Saúde. Departamento de Ações Programáticas Estratégicas. Brasília: Ministério da Saúde, 2012.

BRASIL. Ministério da Justiça. Departamento Penitenciário Nacional. Levantamento Nacional de Informações Penitenciárias Infopen Mulheres - junho de 2014. Brasília, 2015. Disponível em: <http://www.justica.gov.br/noticias/estudo-traca-perfilda-populacao-penitenciaria-feminina-no-brasil/relatorio-infopen-mulheres.pdf.> Acesso em: 06 nov 2015.

BRASIL. Ministério da Saúde. Ministério da Justiça. Portaria Interministerial $\mathbf{n}^{\mathbf{0}} \mathbf{1}$, de 2 de janeiro de 2014. Institui a Política Nacional de Atenção Integrada à Saúde das Pessoas Privadas de Liberdade no Sistema Prisional (PNAISP) no âmbito do Sistema Único de Saúde (SUS). (Acesso em 2015 julho 04) Disponível em: http://bvsms.saude.gov.br/bvs/saudelegis/gm/2014/pri0001_02_01_2014.html

BRASIL. Ministério da Saúde. Ministério da Justiça. Portaria no 482, de 1 de abril de 2014b - Institui normas para a operacionalização da Política Nacional de Atenção 
Integral à Saúde das Pessoas Privadas de Liberdade no Sistema Prisional (PNAISP) no âmbito do Sistema Único de Saúde (SUS). Disponível em: http://www.conasems.org.br/index.php/comunicacao/ultimas-noticias/3628-nota-pnaisp BRASIL. Ministério da Saúde. Portaria no 305, de 10 de abril de 2014c. Institui normas para o cadastramento no Sistema de Cadastro Nacional de Estabelecimentos de Saúde (SCNES) das Equipes e Serviços que farão parte da Atenção Básica de Saúde Prisional. Disponível em: http://bvsms.saude.gov.br/bvs/saudelegis/sas/2014/prt0305_10_04_2014.html DIAS, R. Políticas públicas: princípios, propósitos e processos. São Paulo: Atlas, 2012. GONCALVES, J. P. P. et al . Prontuário Eletrônico: uma ferramenta que pode contribuir para a integração das Redes de Atenção à Saúde. Saúde debate, Rio de Janeiro , v. 37, n. 96, p. 43-50, r. ma2013 . Disponível em $<$ http://www.scielo.br/scielo.php?

script=sci_arttext\&pid=S0103-11042013000100006\&lng=pt\&nrm=iso $>$. acessos em 02 dez. 2015. http://dx.doi.org/10.1590/S0103-11042013000100006. MARQUES, V. T.; FONSECA, V.; NOGUEIRA JUNIOR, G. R.; OLIVEIRA, S. R. M.; NOVAES, J. L.; OLIVEIRA, L. E.; LEITE, T. H. O.; AMARAl, D. L.; FARO, G.N. Perfil dos presos no Estado de Sergipe e Identificação de Políticas Públicas para Egressos. Pesquisa em políticas públicas no Estado de Sergipe. São Cristóvão: Editora UFS, 1, 323-344, 2014.

UNIDOC. OPAS/OMS- UNB. Guia sobre gênero, hiv/aids, coinfecções no sistema prisional UNIDOC: 2012. 63p.

Disponível em: http://www.unodc.org/documents/lpobrazil/Topics_aids/Publicacoes/GUIA_SOBRE_GENERO_HIV_em_prisoes_2012.pdf World Health Organization. WHO. First International Conference on Health Promotion, Ottawa, 21 November 1986. Ottawa Charter. [Internet]. Ottawa: WHO; 1986 [consultado 20 Nov 2011]. Disponível em: $\quad$ www.who.int/hpr/NPH/docs/ottawa_charter_hp.pdf World Health Organization. Prisons and Health. WHO, Regional Office for Europe. Copenhagen: Organization Regional Office for Europe; 2014. (Acesso em 2015 julho 04) Disponível em: http://www.euro.who.int/pubrequest 